\title{
The Risks of Developing Adverse Outcomes According to Geriatric Status in Patients with Coronary Heart Disease with Plannedaorto-coronary Artery Bypass Grafting
}

\author{
${ }^{1}$ Nina I. Zhernakova, ${ }^{2}$ Andrey A. Chmelnickii, ${ }^{3}$ Andrey N. Il'nickii, ${ }^{4}$ Elvira E. Satardinova, ${ }^{5}$ Tichon \\ Yu.Lebedev \\ ${ }^{1,5}$ Federal State Autonomous Educational Institution of Higher Education "Belgorod State National Research \\ University", Belgorod, Russia, ${ }^{2}$ Non-profit organization Research Medical Center "Gerontology", Moscow, \\ Russian Federation, ${ }^{3}$ Saint Petersburg Institute of Bioregulation and Gerontology, Saint Petersburg, Russia , ${ }^{4}$ Irkutsk \\ State Medical Academy of Postgraduate Education - Branch Campus of the Federal State Budgetary Educational \\ Institution of Further Professional Education "Russian Medical Academy of Continuing Professional Education" of \\ the Ministry of Healthcare of the Russian Federation, Irkutsk, Russia \\ *Email: zhernakova@bsu.edu.ru
}

Received: 21st October 2017 Accepted: 16th November 2017, Published: 31st December 2017

\begin{abstract}
The article assesses the risks of developing adverse outcomes in patients with coronary heart disease who underwent planned aorto-coronary artery bypass grafting according to geriatric status using such scales as the Cardiovascular Health Study frailty criteria (CHS-NHLBI), the MacArthur Study of Successful Aging, as well as 5 meter gait speed. We determined the cumulative indexof "lethal outcome + myocardial infarction + acute cerebral circulation disorder" in the early postoperative period in such patients. We proved in this article that the presence of senile asthenia syndrome and its progress was important in the increase in the risk of development of adverse outcomes after aorto-coronary artery bypass grafting.
\end{abstract}

Keywords: Geriatric Status, Risk Factors, Ischemic Heart Disease, Aorto-Coronary Artery Bypass Grafting, Senile Asthenia Syndrome.

\section{Introduction}

Coronary heart disease ranks first in cardiovascular mortality - more than $53 \%$ in the leading position among causes of death, hospitalizations and disability. Despite the myocardial revascularization, primarily aorto-coronary artery bypass grafting, it has become a routine method for treating the CHD in recent decades, which significantly reduces mortality and improves the quality of life of patients in older age groups; but the socioeconomic efficiency of aorto-coronary arterybypass grafting remains low, since it does not lead to a decrease in the number of disabled people [1, 2, 3].

An increase in the average life expectancy in the developed countries leads to an increase in the total population of elderly patients with coronary heart disease $[4,5]$. As a consequence, the proportion of patients of older age groups undergoing the aortocoronary artery bypass grafting increases. Age is one of the significant factors that determine the increased risk of aorto-coronary artery bypass grafting, which is included in all prognostic scales. The issue of whether the adverse effect of age on the number of cardiovascular complications persists after the completion of the stage of surgical revascularization has not been fully investigated. There are still some debates on the clinical, ethical and socio-economic feasibility of performing the surgical myocardial revascularization in patients of older age groups $[1,6$, 7].

An increase in safety and clinical efficacy, as well as the improvement of surgical techniques, enabled to expand indications for interventions and significantly increase the number of patients undergoing aortocoronary artery bypass grafting in the Russian Federation. However, the urgency of the selection of patients, the validity of surgical intervention and the commitment of doctors to adhere to the international recommendations for myocardial revascularization increase in connection with the increased availability of such surgeries. A special group in these questions is represented by elderly and senile patients $[4,5,6$, 8]. The surgery of aorto-coronary artery bypass grafting removes the symptoms of angina pectoris, improves the tolerability of physical activity, improves the quality of life, reduces mortality in some groups of patients [2]. However, the myocardial revascularization is often accompanied by the complications, the most frequent of which are the myocardium damage and the myocardial infarction. According to the data of different authors, the proportion of patients with perioperative MI, which has developed in connection with the surgery, ranges from $2 \%$ to $20 \%$ [2, 3, 7] - the intraoperative myocardial damage is detected in the prevailing number of patients [2].

Thus, in connection with the above, the assessment of the risks of adverse outcomes development according to the geriatric status in patients with the coronary heart disease, which are indicated for planned aortocoronary artery bypass grafting, is of high practical importance.

\section{Objective}

To assess the risk of adverse outcomes development in patients with CHD who underwent planned aorto- 
coronary artery bypass grafting, according to geriatric status.

\section{Materials and Methods}

The study included 482 people. To objectify the evaluation of geriatric status, the patients of older age groups were divided into patients without senile asthenia syndrome $(\mathrm{n}=144$ patients $)$ and with senile asthenia syndrome ( $\mathrm{n}=152$ patients). We assessed the status of the studied middle-aged patients $(n=$ 186 patients) as a control group:

a) a group of middle-aged patients aged $55.6 \pm 2.8$ years old (mean age 45 to 59 years old, $\mathrm{n}=152$ patients);

b) a group of elderly patients without senile asthenia aged $67.8 \pm 3.1$ years old (mean age 60 to 74 years old, $\mathrm{n}=14 \overline{4}$ patients);

c) a group of elderly patients with senile asthenia aged $68.9 \pm 3.2$ years old (mean age 60 to 74 years old, $\mathrm{n}=152$ patients);

The study was conducted using a variety of scales used in the geriatric practice: the Modified Cardiovascular Health Studyfrailty criteria (CHSNHLBI), the MacArthur Study of Successful Aging, as well as 5 meter gait speed. The assessment was carried out 1 month after the planned aorto-coronary artery bypass grafting.
We also assessed the contribution of the syndrome of senile asthenia to the risks of perioperative complications after the aorto-coronary artery bypass grafting, such as myocardial infarction and acute cerebrovascular accident in the first 5 days after surgery, postoperative development of cognitive deficits, cardiac rhythm and conduction disorders, bleeding developmentwithin 15 days after the aortocoronary artery bypass surgery, lethality during the year and the cumulativeindexof "lethal outcome + myocardial infarction + acute cerebral circulation disorder" in the early postoperative period (30 days).

The statistical processing of research materials was carried out on a personal computer using STATISTICA 8.0 application software package (StatSoft Inc., USA).

\section{Results and Discussion}

In the course of thesis research, we assessed the risks of developing adverse outcomes in patients with CHD who underwent a planned aorto-coronary artery bypass grafting, using a variety of scales used in the geriatric practice: the mODIFIED Cardiovascular Health Study frailty criteria (CHS-NHLBI), the MacArthur Study of Successful Aging, as well as 5 meter gait speed. The assessment was carried out 1 month after the planned aorto-coronary artery bypass grafting (Table 1).

Table 1

Determination of the Risk of Adverse Outcomes Development in Patients with and without Senile Asthenia (points, $\mathbf{M} \pm \mathbf{m}$ )

\begin{tabular}{|l|l|l|l|l|}
\hline $\begin{array}{l}\text { Scales for stratifying the risks of } \\
\text { adverse outcomes development } \\
\text { used in geriatric practice }\end{array}$ & $\begin{array}{l}\text { Middle-aged } \\
\text { patients }(\mathrm{n}= \\
186)\end{array}$ & $\begin{array}{c}\text { The elderly } \\
\text { patients with } \\
\text { SA }(\mathrm{n}=144)\end{array}$ & $\begin{array}{c}\text { The elderly patients } \\
\text { without SA }(\mathrm{n}= \\
152)\end{array}$ & $\begin{array}{c}\text { Corrected OR (95\% } \\
\text { preclinical studies) }\end{array}$ \\
\hline $\begin{array}{l}\text { Modified Cardiovascular Health } \\
\text { Study (CHS) }\end{array}$ & $1.6 \pm 0.7$ & $2.1 \pm 1.4 *$ & $3.1 \pm 1.8 * * * * *$ & $1.26(0.97-1.63)$ \\
\hline $\begin{array}{l}\text { MacArthur Study of Successful } \\
\text { Aging }\end{array}$ & $1.2 \pm 0.9$ & $1.4 \pm 1.1$ & $2.1 \pm 1.4 * * * * *$ & $1.24(0.90-1.70)$ \\
\hline 5 meter gait speed (sec.) & $4.6 \pm 1.3$ & $6.2 \pm 2.8 *$ & $7.2 \pm 2.7 * * * * *$ & $2.63(1.17-5.90)$ \\
\hline
\end{tabular}

$* \mathrm{p}<0.05$ the difference between the indices is significant between the groups of middle aged and older patients without SA

$* p<0.05$ the difference between the indices is significant between the groups of middle aged and older patients with SA

$* p<0.05$ the difference between the indices is significant between the groups of middle aged and older patients with and without SA

We obtained the following data: the risk of developing adverse cardiovascular health outcomes according to the Modified Cardiovascular Health Study (CHS) was significantly higher in older patients with senile asthenia compared with the middle-aged patients, and was $3.1 \pm 1.8$ points, $\mathrm{p}$ $<0.05$, and significantly higher in older patients without the senile asthenia syndrome compared with the middle-aged patients, $\mathrm{p}<0.05$, and amounted to $2.1 \pm 1.4$ points. In the groups of older patients, the patients with senile asthenia syndrome have a significantly higher risk of adverse outcomes development by 1.5 times compared with the patients without senile asthenia syndrome, $\mathrm{p}<0.05$, the difference in indices is significant between the groups of older patients with and without senile asthenia.

According to the healthy aging scale, we noted the following patterns: the elderly patients with senile asthenia syndrome have a significantly higher risk of adverse outcomes development compared with the middle-aged patients, which is $2.1 \pm 1.4$ points and $1.2 \pm 0.9$ points, respectively, $\mathrm{p}<0.05$, and have a significantly higher risk of adverse outcomes development by 1.5 . times compared with the older patients without senile asthenia, which is $2.1 \pm 1.4$ points and $1.4 \pm 1.1$ points, respectively, $\mathrm{p}<0.05$. 
However, there were no significant differences between the risks of adverse outcomes development in the middle-aged patients and elderly patients without senile asthenia syndrome, $\mathrm{p}>0.05$.

According to 5 meter gait speed, we found that it was $7.2 \pm 2.7$ seconds for the older patients with senile asthenia syndrome, which was significantly higher than in older patients without senile asthenia syndrome - 6.2 22.8 seconds, $\mathrm{p}<0.05$, and significantly higher in the middle-aged patients by 1.9 times, which was $4.6 \pm 1.3$ seconds, $\mathrm{p}<0.05$.

Among the criteria included in the scale of cardiovascular health assessment, the presence of senile asthenia syndrome significantly correlated with the following criteria in comparison with patients without senile asthenia syndrome: postoperative cognitive deficits $(\mathrm{r}=+0.914, \mathrm{p}<0.02)$; LDL level is higher than $3.5 \mathrm{mmol} / \mathrm{l}(\mathrm{r}=+0.850, \mathrm{p}<0.03)$; left ventricular ejection fraction is less than $50 \%(\mathrm{r}$ $=+0.765, \mathrm{p}<0.002)$; body mass deficit $(\mathrm{r}=+0.718$, $\mathrm{p}<0.05)$.
Among the criteria included in the scale of healthy aging assessment, the following indicators associated with the development of senile asthenia syndrome correlated with a high risk of adverse outcomes: a decrease in 5 meter gait speed $(\mathrm{r}=+0.816, \mathrm{p}<0.05)$, postoperative cognitive deficits $(r=+0.904, p<0.03)$.

We further assessed the contribution of the syndrome of senile asthenia to the risks of perioperative complications after the aorto-coronary artery bypass grafting, such as myocardial infarction and acute cerebrovascular accident in the first 5 days after surgery, postoperative development of cognitive deficits, cardiac rhythm and conduction disorders, bleeding developmentwithin 15 days after the aortocoronary artery bypass surgery, lethality during the year and the cumulativeindexof "lethal outcome + myocardial infarction + acute cerebral circulation disorder" in the early postoperative period (30 days) (Table 2).

Table 2

Development of Adverse Outcomes of Patients with CHD after Planned Aorto-Coronary Artery Bypass Grafting with and without Senile Asthenia Syndrome (\%)

\begin{tabular}{|c|c|c|c|}
\hline Adverse outcome & $\begin{array}{l}\text { Middle-aged } \\
\text { patients }(\mathrm{n}= \\
186)\end{array}$ & $\begin{array}{l}\text { The older age groups } \\
\text { without } \mathrm{SA}(\mathrm{n}=144)\end{array}$ & $\begin{array}{l}\text { The older age } \\
\text { groups with SA } \\
(\mathrm{n}=152)\end{array}$ \\
\hline Perioperative number of MI (\%) & 5.4 & 6.1 & $11.5 * *, * * *$ \\
\hline $\begin{array}{l}\text { Perioperative number of cerebral circulation acute } \\
\text { disorders }(\%)\end{array}$ & 8.2 & 7.8 & $12.6 * * * * *$ \\
\hline Postoperative development of cognitive deficits & 3.3 & $9.6^{*}$ & $16.9 * *, * * *$ \\
\hline $\begin{array}{l}\text { Postoperative disturbances of cardiac rhythm and } \\
\text { conduction }\end{array}$ & 1.5 & $3.6^{*}$ & $4.5^{* *}$ \\
\hline Bleeding development & 2.1 & $5.4^{*}$ & $5.9 * *$ \\
\hline Lethality during the year & 1.3 & $2.5^{*}$ & $6.9 * *, * * *$ \\
\hline $\begin{array}{l}\text { The cumulative index of "lethal outcome }+ \\
\text { myocardial infarction }+ \text { acute cerebral circulation } \\
\text { disorder" in the early postoperative period ( } 30 \text { days) }\end{array}$ & 6.7 & 9.1 & $22.6 * * * * *$ \\
\hline
\end{tabular}

Thus, such complications as postoperative development of cognitive deficits $(9.6 \%$ and $3.3 \%$, respectively), postoperative cardiac rhythm and conduction disorders $(3.6 \%$ and $1.5 \%$, respectively), bleeding development ( $5.4 \%$ and $2.1 \%$, respectively) and lethality rate during the year $(2.5 \%$ and $1.3 \%$, respectively) were significantly more frequent in elderly patients without senile asthenia syndrome compared with the middle-aged patients, $\mathrm{p}<0.05$. The difference in indicators is significant between the middle-aged and older groups without the senile asthenia syndrome. The development of all adverse outcomes was significantly more frequent in elderly patients with senile asthenia syndrome compared with the middle-aged patients, $\mathrm{p}<0.05$. The prevalence of perioperative myocardial infarction and perioperative acute impairment of cerebral circulation is significantly higher in elderly patients with senile asthenia compared with older patients without senile asthenia syndrome $(11.5 \%$ and $12.6 \%$ of older patients with senile asthenia, respectively, compared with $6.1 \%$ and $7.8 \%$ of older patients without senile asthenia, respectively), $\mathrm{p}<0.05$. The difference in indicators is significant between the groups of older patients with and without senile asthenia syndrome. Also, the statistically significant differences were 
found in the same groups of patients studied in the prevalence of postoperative cognitive deficits and the lethality rate during 1 year, which amounted to $16.9 \%$ and $6.9 \%$ of older patients with senile asthenia, respectively, and $9.6 \%$ and $2.5 \%$ of older patients without senile asthenia syndrome, respectively, $\mathrm{p}$ $<0.05$. The difference in indicators is significant between the groups of older patients with and without senile asthenia.

The cumulative index of "lethal outcome + myocardial infarction + acute cerebral circulation disorder" in the early postoperative period (30 days) was found in $6.7 \%$ of middle-aged patients, in $9.1 \%$ of older patients without senile asthenia and in $22.6 \%$ of older patients with senile asthenia syndrome, $\mathrm{p}$ $<0.05$. The difference in the indices is significant between the groups of middle-aged and older patients with senile asthenia syndrome, $\mathrm{p}<0.05$, the difference in indicators is significant between the groups of older patients with and without senile asthenia syndrome. Moreover, the cumulative index of "lethal outcome + myocardial infarction + acute cerebral circulation disorder" in the early postoperative period (30 days) in older patients with senile asthenia syndrome exceeded such index in older patients without senile asthenia syndrome by 2.5 times and in comparison with middle-aged patients - by 3.8 times, $\mathrm{p}<0.05$. The difference in the indices is reliable between the groups of middle-aged and older patients with senile asthenia syndrome, $p$ $<0.05$, the difference in the indicators is reliable between the groups of older patients with and without senile asthenia.

Attention was drawn to the fact that the surgical intervention itself in the form of aorto-coronary artery bypass grafting was the starting point for the development of senile asthenia syndrome in patients with preastenia $(\mathrm{r}=+0.718, \mathrm{p}<0.05)$ and the progression of senile asthenia syndrome with its presence $(\mathrm{r}=+0.864, \mathrm{p}<0.002)$. The structure of patients with senile asthenia syndrome changed in the direction of increasing the proportion of patients with its severe forms (Table 3).

Table 3

Senile Asthenia Syndrome in Elderly Patients who underwent Planned Aorto-Coronary Artery Bypass Grafting

\begin{tabular}{|l|c|c|c|c|c|c|}
\hline $\begin{array}{l}\text { Patients' condition } \\
\text { according to the } \\
\text { degree of senile } \\
\text { asthenia syndrome }\end{array}$ & $\begin{array}{c}|c| \\
\text { Factor load of } \\
\text { the } \\
\text { contribution to } \\
\text { risks }\end{array}$ & $\begin{array}{c}\text { Portion in } \\
\text { the SA } \\
\text { structure (\%) }\end{array}$ & $\begin{array}{c}\text { Factor load } \\
\text { of the } \\
\text { contribution } \\
\text { to risks }\end{array}$ & $\begin{array}{c}\text { Portion } \\
\text { in the SA } \\
\text { structure } \\
(\%)\end{array}$ & $\begin{array}{c}\text { Factor load } \\
\text { of the } \\
\text { contributio } \\
\text { n to risks }\end{array}$ & $\begin{array}{c}\text { Portion in } \\
\text { the SA } \\
\text { structure }(\%)\end{array}$ \\
\hline $\begin{array}{l}\text { Satisfactory geriatric } \\
\text { status }\end{array}$ & 0.000 & 24.6 & 0.000 & 22.8 & 0.000 & 19.3 \\
\hline $\begin{array}{l}\text { Snile pre-asthenia } \\
\text { syndrome }\end{array}$ & 0.126 & 22.8 & 0.202 & 13.7 & 0.187 & 10.2 \\
\hline Mild SA & 0.504 & 35.2 & 0.404 & 26.8 & 0.318 & 23.4 \\
\hline Moderate SA & 0.601 & 14.2 & 0.12 & 25.9 & 0.615 & 29.7 \\
\hline Large SA & 0.824 & 3.2 & 0.925 & 10.8 & 0.894 & 17.4 \\
\hline Total & & 100 & & 100 & & 100 \\
\hline
\end{tabular}

Having analysed the data obtained, we can conclude that the important thing was not only the absence of senile asthenia syndrome, but also the lack of its progressionin the formation of the degree of risk of adverse outcomes development after the aortocoronary artery bypass grafting.

\section{Summary}

1. Among the criteria included in the scale of cardiovascular health assessment, the presence of senile asthenia syndrome significantly correlated with the following criteria in comparison with patients without senile asthenia syndrome: postoperative cognitive deficits $(\mathrm{r}=+0.914, \mathrm{p}<0.02)$; LDL level is higher than $3.5 \mathrm{mmol} / \mathrm{l}(\mathrm{r}=+0.850, \mathrm{p}<0.03)$; left ventricular ejection fraction is less than $50 \%(\mathrm{r}$ $=+0.765, \mathrm{p}<0.002)$; body mass deficit $(\mathrm{r}=+0.718$, $\mathrm{p}<0.05)$.
2. Among the criteria included in the scale of healthy aging assessment, the following indicators associated with the development of senile asthenia syndrome correlated with a high risk of adverse outcomes: a decrease in 5 meter gait speed $(\mathrm{r}=+0.816, \mathrm{p}<0.05)$, postoperative cognitive deficits $(r=+0.904, p<0.03)$. 3 . The cumulative index of "lethal outcome + myocardial infarction + acute cerebral circulation disorder" in the early postoperative period (30 days) in older patients with senile asthenia was greater than that in older patients without senile asthenia by 2.5 times and in comparison with middle-aged patients by 3.8 times.»

4. The important thing was not only the absence of senile asthenia syndrome, but also the lack of its progressionin the formation of the degree of risk of 
adverse outcomes development after the aortocoronary artery bypass grafting.

\section{References}

[1]Ruda, M.Ya., 2007. Myocardial Infarction with ST Segment Elevation.Manual on Atherosclerosis and Coronary Heart Disease.Edited by E.I. Chazov, V.V. Kukharchuk, S.A. Boytsov.M., 2007: 626-725.

[2]Yakovleva, L.N., Peremot, Ya.O., 2013. Factors Affecting the Long-Term Forecast in Patients with Coronary Heart Disease who Underwent the AortoCoronary Artery Bypass Grafting. Emergency Medicine, 7(54): 128-133.

[3]Reffelmann, T.,Kloner, R.A., 2006. The no-reflow phenomenon: A basic mechanism of myocardial ischemia and reperfusion. Basic Res. Cardiol., 101: 359-372.

[4]Ilnitsky, A.N., Proschayev, K.I., 2012. Specialized Geriatric Examination. Gerontological Journal named afterrV.F. Kuprevich, 4-5: 66-84.

[5]Berrut, G., Andrieu, S., Bergma, H., Cassim, B., Cerreta, F., Cesari, M., Cha, H.B., Chen, L.K., Cherubini, A., Forette, F., Franco, A., Guimaraes, R., Robledo, L.M., Jauregui, J., Khavinson, V., Lee, W.J., Benetos, A., 2013. Promoting access to innovation for frail old persons. The Journal of Nutrition, Health \& Aging, 17(8): 688-693.

[6]Proshchayev, K.I., Ilnitsky, A.N., Krivetsky, V.V., Varavina, L.Yu., Kolpina, L.V., Gorelik, S.G., Fesenko, V.V., Krivtsunov, A.N., 2013. Features of Clinical Examination of Elderly and Senile Patients. The Successes of Gerontology, 3: 79-82.

[7] Roffi, M., Patrono, C., Collet, J-P. et al., 2016. 2015 ESC Guidelines for the Management of Acute Coronary Syndromes in Patients presenting without Persistent ST-Segment Elevation. European Heart Journal, 37(3):267-315. doi: 10.1093/eurheartj/ehv320.

[8] Armstrong, P.W., Gershlick, A.H., Goldstein, P., Wilcox, R., Danays, T., Lambert, Y., Sulimov, V., Rosell Ortiz, F., Ostojic, M., Welsh, R.C., Carvalho, A.C., Nanas, J., Arntz, H.R., Halvorsen, S., Huber, K., Grajek, S., Fresco, C., Bluhmki, E., Regelin, A., Vandenberghe, K., Bogaerts, K., Van de Werf, F., 2013. Fibrinolysis or primary PCI in ST-segment elevation myocardial infarction. N. Engl. J. Med., 368(15): 1379-1387. 